\title{
Исследование молекулярно-массового распределения природных полисахаридов и полиацетиленов методом многомерной хроматографии
}

\author{
(C) 2020 Бекташи H.P. \\ Институт Полимерных Материалов НАН Азербайджана, Баку Азербайджанская Республика
}

Поступила в редакцию 21.02 .2020 г.

DOI: $10.17308 /$ sorpchrom.2020.20/2874

Методом многомерной жидкостной хроматографии с использованием ГПХ и обращеннофазовой адсорбционной хроматографии, исследовано молекулярно-массовые и функциональные харктеристики продуктов биосинтеза полисахаридов и полиацетиленовых соединений, базидиальными грибами рода Ganoderma lucidum и Pleurotus ostreatus. Указанные грибы выращивались методом глубинного культивирования в среде, состоящей из пшеничных отрубей на среде Чапека-Докса следующего состава (г/дм $)^{3}: \mathrm{NaNO}_{3}-2, \mathrm{~K}_{2} \mathrm{HPO}_{4}-1, \mathrm{MgSO}_{4} \cdot 7 \mathrm{H}_{2} \mathrm{O}-0.5, \mathrm{KCl}-0.5, \mathrm{FeSO}_{4} \cdot \mathrm{H}_{2} \mathrm{O}-0.01$, глюкоза-30 и $\mathrm{H}_{2} \mathrm{O}$. Культивирование проводилось в термостате при $28^{\circ} \mathrm{C}$. После 10 суток выдержки в составе их мицелл обнаружены полисахариды и полиацетиленовые соединения. Далее образующуюся биомассу грибов измельчали и экстрагировали метиловым эфиром уксусной кислоты и водой. Осадок и экстракт в отдельности разделены в указанной хроматографической системе. Установлено, что в водном экстракте количество полисахаридов достигает до 70-80\%, а в эфирном экстракте содержание полиацетиленовых соединений меняется в пределах $65-70 \%$. Таким образом, метод GPC позволил выявить в составе продуктов биосинтеза 5 фракций, в том числе 4 полисахаридов, состоящие из гексаозы $\left(M_{w}=M_{n}=1085\right)$, гептаозы $\left(M_{w}=M_{n}=1260\right)$ и из двух олигосахаридов с $M_{w}$ и $M_{n} 4390,3600$ и 5450,4500 , соответственно, и одна полиацетиленовая $\left(M_{w}=180, M_{n}=150\right)$. Методом обращенно-фазовой адсорбционной хроматографии в рабочей волне УФ-детектора в составе полиацетиленовой фракции обнаружены 5 подфракций по химической природе относяхщихся к полиацетиленовым кислотам и спиртам сопряженными двойными и тройными связями в различных сочетаниях. С целью изучения химического состава обнаруживаемых подфракции, фракция полиацетилена подвергнута препаративному разделению. Разделение обеспечено в условиях повышенной концентрации экстракта, многократным сбором фракции по соответствующим пикам на АЖХ хроматограмме, которые далее были подвергнуты ИК-спектральному анализу и установлен их функциональный состав. Состав полиацетиленновых соединений подтвержден также хроматографически по объемам удерживания испытываемых соединений с применением соответствующих эталонов.

Ключевые слова: молекулярно-массовое распределение, гель-проникающая хроматография, обращенно-фазовая адсорбционная хроматография, базидиальные грибы, полисахариды, полиацетилены.

\section{Введение}

Известно, что базидиальные грибы являются источниками целого ряда биологически активных веществ: белков, липидов, полисахаридов, органических кислот, ферментов, витаминов, полиацетиленов, которые являются биологически активными продуктами и по сравнению с продуктами химического синтеза менее токсичны и более эффективны [1-3]. Среди них наиболее характерными являются полисахариды (ПС) и полиацетилены (ПА), содержащие реакционноспособные сопряженные трой- 
ные и двойные связи. Использование базидиомицетов в качестве источников ПА соединений и ПС очень перспективно, т.к. открывает дальнейшее применение для получение биологически активных препаратов, которые могут быть использованы в медицине [4-6]. В настоящее время наиболее мощнейшими методами разделения и идентификации подавляющего большинства перечисленных соединений, являются методы высокоэффективной жидкостной хроматографии: эксклюзионной, адсорбционной, ионообменной, тонкослойной хроматографии, и т.д. [7]. В настоящей работе комплексным использованием двухдетекторной эксклюзионной и обращеннофазовой адсорбционной жидкостной хроматографии (ЭЖХ, ОФАЖХ) исследовано молекулярно-массовое распределение и функциональные составы ПС и ПА, источниками получения которых являлись базидиомицеты рода Ganoderma lucidum и Pleurotus ostreatus.

\section{Экспериментальная часть}

Базидиальные грибы рода Ganoderma lucidum и Pleurotus ostreatus выращивались методом глубинного культивирования в среде, состоящей из пшеничных отрубей на среде Чапека-Докса следующего состава (г/дм $\left.{ }^{3}\right): \mathrm{NaNO}_{3}-2, \mathrm{~K}_{2} \mathrm{HPO}_{4}-1$, $\mathrm{MgSO}_{4} \cdot 7 \mathrm{H}_{2} \mathrm{O}-0.5, \mathrm{KCl}-0.5, \mathrm{FeSO}_{4} \cdot \mathrm{H}_{2} \mathrm{O}-0.01$, глюкоза-30 и $\mathrm{H}_{2} \mathrm{O}$. Культивирование проводилось в термостате при $28^{\circ} \mathrm{C}$ в течение 10 дней. Далее образующуюся биомассу грибов измельчали и экстрагировали метиловым эфиром уксусной кислоты (МЭУК) и водой [8]. Осадок и экстракт хроматографировали отдельно. Установлено, что в водном экстракте количество ПС достигает до 70-80\%, в экстракте МЭУК содержание ПА соединений меняется в пределах 65-70\%.

Хроматографические исследования проведены на высокоэффективном жидкостном хроматографе фирмы «Kovo» (Чехия). Была применена двухдетекторная система хроматографирования. Детекторы: рефрактометр и УФ-спектрофотометр (254 нм), колонки с размером $3.3 \times 150$ мм, заполненные сорбентами марки «SeparonSGX» (ЭЖX) пористостью $100 \AA$ и «Separon-SGX C-18» обращенной фазой (ОФАЖХ), размерами частиц 7 мкм. Элюенты: диметилформамид и ацетонитрил $+\mathrm{H}_{2} \mathrm{O}\left(75+25\right.$ об.\%) последовательно, скорость подачи $0.3 \mathrm{~cm}^{3} / \mathrm{Mин,} \mathrm{T}=20-25^{\circ} \mathrm{C}$. Молекулярные массы (МM) и параметры молекулярно-массового распределения (ММР) определены методом ЭЖХ. При этом калибровочную зависимость $\operatorname{lgM}$ от $V_{R}$ в эксклюзионном режиме в диапазоне М $1.5 \times 10^{2}-50 \times 10^{2}$ получили с использованием полисахаридов. Вычисления проведены по методике [9].

\section{Обсуждение результатов}

Продукты биосинтеза, как указано выше, исследованы методами двухдетекторной ЭЖХ и ОФАЖХ, позволяющие параллельно оценить ММ и функциональные характеристики синтезированных продуктов. Результаты ЭЖХ и ОФАЖХ исследований водных и эфирных экстрактов, полученных после обработки культуральной жидкости соответствующих базидиальных грибов (Ganoderma lucidum, Pleurotus ostreatus), представлены в таблице и на рис.1.

Установлено, что между результатами, полученными в случае указанных видов базидиальных грибов существует большое сходство. В обоих случаях по характеру ОФАЖХ хроматограммы можно полагать, что анализируемые продукты состоят из смеси фракций, относящихся к двум разным типам соединений. Первая фракция одновременно фиксируется рефрактометром (рис. 1, кривые $a$ и $a^{\prime}$, пики 1) и УФдетектором (рис. 1, кривая 6 (пики 1-5), характеризующаяся мультиплетным харак- 
тером с пятью максимумами с разными интенсивностями). Это свидетельствует о наличии в ее составе 5 подфракций разной функциональности, хорошо поглощающих излучение в УФ-области. Индивидуальный характер сигнала фракций по рефрактометру связан с близостью физико-химических параметров, особенно оптических плотностей соединений, имеющихся в ее составе.

Таблица. Молекулярно-массовые характеристики ПА и ПС полученных в процессе биосинтеза базидиомицетами Ganoderma licidum (фракции 1-7) и Pleurotus ostreatus (фракции 7-14).

\begin{tabular}{|c|c|c|c|c|c|c|c|}
\hline \multirow{2}{*}{ № фракции } & \multirow{2}{*}{$\begin{array}{c}\text { Название фрак- } \\
\text { ции }\end{array}$} & \multicolumn{2}{|c|}{$\begin{array}{c}\text { Содержание } \\
\text { фракции, } \%\end{array}$} & \multicolumn{2}{|c|}{ ММР } & \multirow{2}{*}{$M_{w} / M_{n}$} & \multirow{2}{*}{$M_{p}$} \\
\cline { 3 - 6 } & в МЭУК & в воде & $M_{w}$ & $M_{n}$ & & \\
\hline 1 & ПА & 74.0 & 6.0 & 180 & 150 & 1.2 & 180 \\
2 & Гексаоза & 11.0 & 42.5 & 1085 & 1085 & 1.0 & 1085 \\
3 & Гептаоза & 18.0 & 31.0 & 1260 & 1260 & 1.0 & 1260 \\
4 & Олигосахарид & 3.0 & 11.5 & 4390 & 3600 & 1.22 & 2430 \\
5 & Олигосахарид & 4.0 & 10.0 & 5450 & 4500 & 1.21 & 4730 \\
6 & --- & - & - & 1912 & 1260 & 1.82 & - \\
7 & --- & - & - & 829 & 229 & 3.62 & - \\
8 & ПА & 71.0 & 8.0 & 180 & 180 & 1.0 & 180 \\
9 & Гексаоза & 12.0 & 40.0 & 1085 & 1085 & 1.0 & 1085 \\
10 & Гептаоза & 7.0 & 33.0 & 1260 & 1260 & 1.0 & 1260 \\
11 & Олигосахарид & 5.0 & 12.0 & 4600 & 3500 & 1.31 & 2985 \\
12 & Олигосахарид & 5.0 & 7.0 & 5600 & 4650 & 1.2 & 4000 \\
13 & --- & - & - & 1806 & 893 & 2.02 & - \\
14 & --- & - & - & 855 & 244 & 3.5 & - \\
\hline
\end{tabular}

Примечание:суммарные ММ продукта в водном (6 и 7) и в экстракте МЭУК (13 и 14).

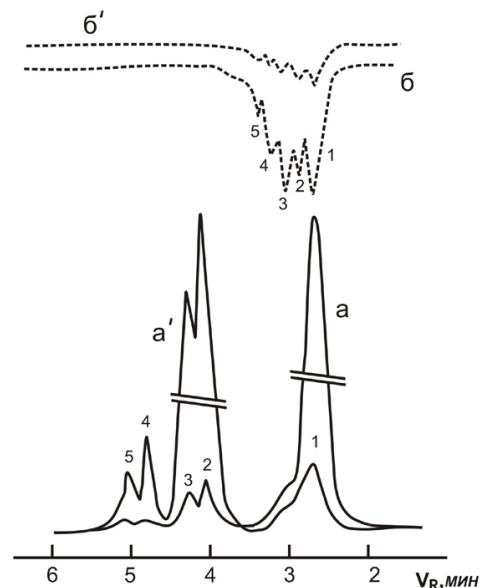

Рис. 1. ОФАЖХ кривые смеси ПА и ПС, полученных в процессе биосинтеза базидиальными грибами рода Ganoderma lucidum, выделенных при экстракции МЭУК (кривые $a$ и б) и водой (кривые $a^{I}$ и $\sigma^{I}$ ). Детекторы: рефрактометрический (сплошная линия), УФ-спектрофотометрический (254 нм) (штриховая линия). Адсорбент Separon SGX C18, элюент ацетонитрил $+\mathrm{H}_{2} \mathrm{O}(75+25$ об.\%), T=20-25ㅇ.

Здесь и на рис.2 детекторы: рефрактометрический (сплошная линия), УФ-спектрофотометрический (254 нм) (штриховая линия).

По результатам физико-химических анализов установлено, что указанные фракции соответствуют ПА соединениям, обладающих высокой степенью ненасыщенности и содержащих многочисленные тройные и двойные связи, т.е. активные 
хромофоры, хорошо поглощающие излучение в УФ-области. Остальные 4 фракции фиксируются только по рефрактометру и относятся к хорошо растворимым в воде полисахаридам, в составе которых основными функциональными группами являются ауксохромные гидроксильные группы не поглощающих УФ излучение (кривая $a$, пики 2-5). По характеру хроматограмм также видно, что в эфирных экстрактах, как и следовало ожидать, количественным преимуществом обладают ПА (кривая $a$ ), а в водных экстрактах ПС (кривая $a^{\prime}$ ). В обоих случаях количество ПА и ПС выделенных из состава биомасс соответствующих базидиомицетов достигает до 70-80 \%.

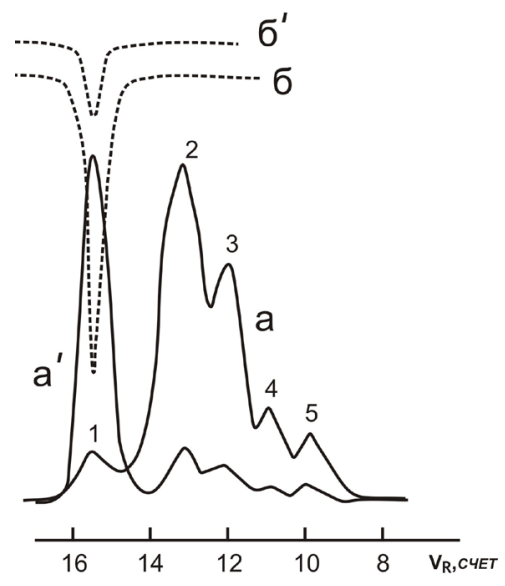

Рис. 2. Эксклюзионные кривые ММР смеси ПА и ПС полученных в процессе биосинтеза базидиальными грибами рода Ganoderma lucidum, выделенных при экстракции метиловым эфиром (кривые $a$ и $\sigma$ ) и водой (кривые $a^{l}$ и $\left.\sigma^{1}\right)$. Адсорбент «Separon $\mathrm{SGX} », \mathrm{D}=100 \AA$, элюент ДМФА $-0.3 \mathrm{~cm}^{3} / \mathrm{мин,} \mathrm{T}=20-25^{\circ} \mathrm{C}, 1 \mathrm{cч}=0.13 \mathrm{~cm}^{3}$.

Изучение ММР экстрактов методом ЭЖХ позволило установить количественное соотношение отдельных фракций в их составе. Выявлены оптимальные условия, обеспечивающие максимальный переход ПА и ПС из культуральной жидкости в МЭУК и воду. Например, содержание ПА в экстракте МЭУК достигает $\sim 70 \%$ (Ganoderma lucidum), количество олигосахаридов в этом случае достигает лишь до 10\%. А в случае водных экстрактов обнаруживается обратное, т.е. фиксируется лишь $6 \%$ фракции ПА, до $80 \%$ фракции ПС с разными значениями $M_{n}$ (таблица). Причем ПА проявленные по рефрактометру, как и в случае ОФАЖХ, и в этом режиме разделения характеризуются узким пиком с максимумом при $V_{R}=15.5$ соответствующей $M_{n}=180$ (рис.2, кривая $a$ ). ЭЖХ анализ подтвердил также полимерную структуру следующих фракций. Так пики 2-5 (рис.2, кривая a) на ЭЖХ хроматограмме исследуемых экстрактов, с максимумами при $V_{R}=9.8$ и 10.2, соответствуют полисахаридам с $M_{n}=4500$ и 3600 (10 и $11.5 \%$ ), а при $V_{R}=12$ и 13 фракциям олигосахаридов с $M_{n}=1260$ (гептаоза) (31\%) и 1080 (тетраоза) (41.5\%).

Как следует из представленных данных, изменение ММ указанных олигосахаридов в таком широком диапазоне отражаются в значениях степени полидисперсности (СП). Причем суммарные значения СП олигосахаридов в экстрактах МЭУК выше (3.62 и 3.5) (таблица, фракции 7 и 14), чем в водных экстрактах (1.82 и 2.02) (фракции, 6 и 13). Исследуемая хроматографическая система позволяет выделить фракции из состава экстрактов со значением СП в довольно низком интервале 1.01.2. Из табличных данных также видно, что в обоих случаях, при использовании базидиомицетов рода Ganoderma lucidum и Pleurotus ostreatus, наблюдаются идентичные закономерности, фиксируется лишь небольшая разница в количественных соотношениях фракций в составе исследуемых экстрактов. Это свидетельствует о том, 
что в подобранных условиях выращивания биомассы, исследуемых базидиальных грибов, как и следовало ожидать, по механизму действия одинаковы. Сравнение УФхроматограмм снятые в ЭЖХ и ОФАЖХ режимах показывает, что в последнем случае селективность системы по функциональности ПА соединений высокая. Так, мультиплетные сигналы фракции ПА, зафиксированных в случае ОФАЖХ (рис.1, кривая $\sigma u \sigma^{\prime}$ ) в ЭЖХ режиме отличаются мономодальностью (рис.2, кривая $\sigma$ и $\sigma^{\prime}$ ).

С целью изучения химического состава обнаруживаемые фракции ПА подвергнуты препаративному разделению. Оно было обеспечено в условиях повышенной концентрации экстракта, многократным сбором фракции по соответствующим пикам ОФАЖХ, зафиксированных по УФ-детектору, которые далее были подвергнуты структурному анализу. В ИК-спектрах ПА были обнаружены следующие функциональные группы: в области $2010 \mathrm{~cm}^{-1}$ - сигнал, характерный для тройной связи; в области 3300 и $2240 \mathrm{~cm}^{-1}$ - сигналы, соответствующие концевым ацетиленовым связям $\equiv \mathrm{C}-\mathrm{H}$ и колебанию связи $\mathrm{C} \equiv \mathrm{C}$, соответственно. Полоса поглощение в области $1640 \mathrm{~cm}^{-1}$ соответствует двойной углеродной связи, интенсивная полоса в области $940 \mathrm{~cm}^{-1}$ свидетельствует о внеплоскостных деформационных колебаниях О-Н в карбоксильных группах. Кроме того, наличие карбоксильных групп подтверждается полосами поглощения в области 2500-2700 и $3000 \mathrm{~cm}^{-1}$. Поглощение в области 1230 и $1290 \mathrm{~cm}^{-1}$ также относится к деформационным колебаниям группы O-H, а также к валентным колебаниям $\mathrm{C}=0$ в карбоксильных группах кислот. Валентные колебания О-Н-связи спиртов поглощают в области 3700-3100 cм-1. Полосы поглощения, наблюдаемые в области 1050 и $3350 \mathrm{~cm}^{-1}$, соответствуют валентным колебаниям связей С-О и О-Н, соответственно.

Таким образом, в результате проводимых исследований по изучению химического состава и структуры смесей ПА, выращиваемых базидиальными грибами, были идентифицированы 5 известных соединений соответственно по пикам 1-5 (рис.1, кривая б). Указанные соединения были зафиксированы последовательно в следующем порядке:

1 - цис-ундека-3,9,10-триен-5,7-дииновая кислота $\mathrm{H}_{2} \mathrm{C}=\mathrm{C}=\mathrm{CH}-\mathrm{C}=\mathrm{C}-\mathrm{C}=\mathrm{C}-\mathrm{CH}=\mathrm{CH}-\mathrm{CH}_{2}-\mathrm{COOH}$;

2 - цис-ундека-2-ен-4,6,10-трииновая кислота $\mathrm{HC} \equiv \mathrm{C}_{-} \mathrm{CH}_{2}-\mathrm{CH}_{2}-\mathrm{C} \equiv \mathrm{C}-\mathrm{C} \equiv \mathrm{C}-\mathrm{CH}=\mathrm{CH}_{2}-\mathrm{COOH}$;

3 - цис-нона-4-ен-6,8-дииновая кислота $\mathrm{HC} \equiv \mathrm{C}-\mathrm{C} \equiv \mathrm{C}-\mathrm{CH}=\mathrm{CH}-\mathrm{CH}_{2}-\mathrm{CH}_{2}-\mathrm{COOH}$;

4 - цис-ундека-3-ен-5,7,10-триин-1-ол- $\mathrm{HC} \equiv \mathrm{C}-\mathrm{CH}_{2}-\mathrm{C} \equiv \mathrm{C}-\mathrm{C} \equiv \mathrm{C}-\mathrm{CH}=\mathrm{CH}-\mathrm{CH}_{2}-\mathrm{CH}_{2} \mathrm{OH}$;

5 - дека-цис-2-транс-8-диен-4,6 диин-1-ол- $\mathrm{CH}_{3}-\mathrm{CH}=\mathrm{CH}-\mathrm{C} \equiv \mathrm{C}-\mathrm{C} \equiv \mathrm{C}-\mathrm{CH}=\mathrm{CH}-\mathrm{CH}_{2} \mathrm{OH}$.

\section{Заключение}

Результаты исследований методом многомерной жидкостной хроматографии, в системе ГПХ/обращенно-фазовая адсорбционная хроматография по изучению процесса биосинтеза базидиомицетов, выявляют возможности, кроме ПС и ПА, синтезировать также другие биологически активные органические вещества медицинского назначения. Подобранные условия хроматографического разделения позволяют осуществить контроль за условиями культивирования, структуры и составом продуктов биосинтеза, а также за эффективностью действия различных грибов в отдельности.

\section{Список литературы}

1. Белова Н.В. // Растительные ресурсы. 1991. T. 27. № 2. C. 8-17.

2. Автономова А.В., Карапетян А.Р., Котелов М.С. и др. // Башкирский химический журнал. 2011. Т. 18. № 4. С. 32-37.

Бекташи Н.Р. / Сорбционные и хроматографические процессы. 2020. Т. 20. № 3. С. 378-384 
3. Жерносеков Д.Д., Сакович В.В. // Вестник Полесского Государственного Универcumema. 2018. № 1. C. 3-12.

4. Мурадов П.З., Алиев И.А., Аббасова Д.М. // Вестник МГОУ, серия Естественные науки. 2009. № 2. С. 57-60.

5. Алиева С.Р., Велиев М.Г., Исмаилов Э.И. и др. // Журнал иммунопатология, аллергология, инфектология. 2009. № 2. С. 158-159.

6. Muradov P.Z, Veliyev M.G, Yagubova G.G. et al. // 24 Ulusal Kimya
Kongresi,Türkiye, Zonguldak 29 haziran-2temmuz, 2010, BPO 28.

7. Хроматография / под ред. Э.Хефтмана. М. Мир. 1986. 422 c.

8. Караюсифова А.К., Гахраманова А.К., Ягубова Г.Г. и др. // Вестник МГОУ, серия Естественные науки. 2011. № 1. С. 25-29.

9. Амирасланова М.Н., Абдуллаева Н.Р., Алиева Р.В., Бекташи Н.Р. и др. // Сорбционные и хроматографические прочессы. 2018. T. 18. № 6. C. 884-889.

\title{
A study of the molecular weight distribution of natural polysaccharides and polyacetylenes by means of multidimensional chromatography
}

\author{
(C) 2020 Bektashi N.R.
}

Institute of Polymer Materials of the National Academy of Sciences of Azerbaijan, Baku, Azerbaijan Republic

The molecular-weight and functional characteristics of the products of the biosynthesis of polysaccharide and polyacetylene compounds by basidiomycetes genus Ganoderma lucidum and Pleurotus ostreatus were studied using multidimensional liquid chromatography together with gel permeation chromatography and reversed-phase adsorption chromatography. The fungi were grown by means of submerged cultivation in a medium consisting of wheat bran on the Chapek-Doks medium of the following composition (g/l): $\mathrm{NaNO}_{3}$ $-2, \mathrm{~K}_{2} \mathrm{HPO}_{4}-1, \mathrm{MgSO}_{4} \cdot 7 \mathrm{H}_{2} \mathrm{O}-0.5, \mathrm{KCl}-0.5, \mathrm{FeSO}_{4} \cdot \mathrm{H}_{2} \mathrm{O}-0.01$, glucose-30\%, and $\mathrm{H}_{2} \mathrm{O}$. The cultivation was performed in a thermostat at $280^{\circ} \mathrm{C}$. After 10 days of exposure, polysaccharides and polyacetylene compounds were found in the fungi mycelium. The resulting fungal biomass was then ground and extracted with a methyl ether of acetic acid and water. The precipitate and the extract were analysed separately using the said chromatography system. The analysis demonstrated that the water extract contained $70-80 \%$ of polysaccharides, and the ether extract contained $65-70 \%$ of polyacetylene compounds. Thus, the GPC demonstrated that the products of biosynthesis contained 5 fractions, including 4 fractions of polysaccharides, consisting of hexaose $\left(M_{w}=M_{n}=1085\right)$, heptaose $\left(M_{w}=M_{n}=1260\right)$ and two oligosaccharides with $M_{w}$ and $M_{n} 4390,3600$ and 5450,4500 , respectively, and one polyacetylene fraction $\left(M_{w}=180, M_{n}=150\right)$. The reversed-phase adsorption chromatography with UV-detection demonstrated that the polyacetylene fraction contained 5 subfractions, which by their chemical nature are related to polyacetylene acids and alcohols conjugated by various combinations of double and triple bonds. In order to study the chemical composition of the detected subfractions, the polyacetylene fraction was subjected to preparative separation. The separation was performed with increased extract concentration by means of multiple fraction collection according to the corresponding peaks on the LSC chromatogram. The peaks were then subjected to IR spectroscopy, which allowed us to determine their functional composition. The composition of the polyacetylene compounds was also confirmed chromatographically by the retention volumes of the tested compounds using the corresponding standards.

Keywords: molecular weight distribution, gel permeation chromatography, reversed-phase adsorption chromatography, basidiomycetes, polysaccharides, polyacetylenes.

\section{References}

1. Belova N.V., Plant resources, 1991, Vol. 27, No 2, pp.8-17.

2. Avtonomova A.V., Karapetyan A.R., Kotelov M.S. et al., Bashkir Chemical Journal, 2011, Vol. 18, No 4, pp. 32-37.

3. Zhernosekov D.D., Sakovich V.V., Bulletin of Polessky State University, 2018, No 1, pp. 312.
4. Muradov P.Z., Aliev I.A., Abbasova D.M., Vestnik MGOU, a series of Natural sciences, 2009, No 2, pp. 57-60.

5. Aliyev S.R., Veliev M.G., Ismailov E.I. et al., Journal of immunopathology, allergology, infectology, 2009, No 2, pp. 158-159.

6. Muradov P.Z, Veliyev M.G, Yagubova G.G. et al., 24 Ulusal Kimya Kongresi, Türkiye, 
Zonguldak 29 haziran -2-temmuz, 2010, BPO 28.

7. Khromatographiya, under the editorship of E. Heftman, M., Mir, 1986, 422 p.

8. Karayusifova A.K., Gakhramanova A.K., Yagubova G.G. et al., Vestnik $M G O U$, a series of Natural Sciences, 2011, No 1, pp. 25-29.

Бекташи Назим Рауф оглы - к.Х.н., доцент лаборатории физико-химического анализа, Институт Полимерных Материалов Национальной Академии наук Азербайджана, гБаку Азербайджанская Республика
9. Amiraslanova M.N., Abdullaeva N.R., Aliyeva R.V., Bektashi N.R. et al., Sorptsionnye I kromatograficheskie protsessy, 2018, Vol. 18, No 6, pp. 884-889.

Bektashi Nazim Rauf oglu - Associate Professor of the Laboratory of Physical-Chemical Analysis, Institute of Polymer Materials National Academy of Sciences of Azerbaijan, Baku, Azerbaijan Republic, nazimbektash@gmail.com 